\title{
Integration of 3D numerical modelling and InSAR deformation monitoring to characterise block caving induced surface subsidence
}

\author{
K.S. Woo Geological Engineering, The University of British Columbia, Canada \\ E. Eberhardt Geological Engineering, The University of British Columbia, Canada \\ P. Ghuman MDA Systems Ltd., Canada \\ D. Stead Resource Geotechnics, Simon Fraser University, Canada
}

\begin{abstract}
Although the economic benefits of block caving are appealing, the mass extraction of ore inevitably causes significant ground deformations that may adversely affect sensitive infrastructure on surface. Sophisticated $3 D$ numerical modelling has recently been employed as a means to help assess subsidence magnitudes, extent and impacts. At the same time, uncertainty and variability associated with geological heterogeneity and rock mass properties results in model uncertainty and the need for models to be calibrated and constrained. This study examines the use of $3 D$ numerical methods for modelling block caving induced surface subsidence and means to calibrate and constrain these complex models. The latter is addressed through the use of high-resolution satellite Interferometric Synthetic Aperture Radar (InSAR) data acquired through Canada's second generation radar satellite, RADARSAT-2. Preliminary results are presented for a detailed multi-disciplinary study involving the Palabora block cave mine in South Africa.
\end{abstract}

\section{Introduction}

As the lowest cost underground mining method, block caving is increasingly being favoured by a number of mining companies targeting low-grade orebodies at depth or transitioning from deep open pit operations that are nearing the end of their mine life, due to the economic benefits the method provides. As a mass mining method block caving may lead to significant ground deformations and subsidence on surface that may in turn impose deformations to nearby mine infrastructure and buildings. To better manage this potential risk, numerous studies have been undertaken to better characterise and assess the magnitudes and extent of caving induced subsidence relative to the location of the undercut at depth. Many of these involve empirical relationships that relate rock mass quality to break angles (e.g. Laubscher, 2000), but do not fully account for the influence of stress-strain interactions and geological heterogeneity that may significantly affect the ground deformation profile, including magnitudes and reach.

Over the past 20 years, investigators have increasingly turned to advanced 2D and 3D numerical modelling to improve the characterisation, assessment and understanding of block caving subsidence dynamics and surface-underground interactions (e.g. Karzulovic et al., 1999; Gilbride et al., 2005; Beck and Pfitzner, 2008; Sainsbury et al., 2008; Vyazmensky, 2008). As in any modelling study, the results depend on the initial conditions and material properties assumed. These can vary greatly in accordance with the geological heterogeneity and variability encountered on-site, with ranges of input properties being more likely than a single value. Nevertheless, numerical methods do enable the treatment of such complexities as varying rock mass strength, geological heterogeneity, undercut depth and interactions between the developing block cave and overlying surface. The ground response to these varying factors can then be assessed as to their impact on block caving induced subsidence patterns.

To constrain these complex models, surface monitoring data is required. Monitoring of geodetic survey prisms and/or tiltmeters represent one working option, however, these suffer from issues of instrument reliability, data collection/transmission, and spatial coverage for what is effectively a sparse network of point measurements. This paper examines this issue and investigates satellite-based InSAR as another means to obtain ground surface deformation data to constrain advanced 3D numerical models. InSAR imaging data are presented for the Palabora block caving operation in South Africa, where a large $800 \mathrm{~m}$ high pit slope failure 
occurred in response to block caving activities below the pit. Comparisons are made between preliminary model results, using standard constitutive models (Mohr-Coulomb) and field estimated rock mass properties, and InSAR deformation maps to explore spatial relationships between the undercut, cave and open pit and the ground movements that have occurred in response to block caving. Also discussed is the use of 3D data immersion and visualisation techniques to fully integrate and interrogate the numerical modelling and InSAR results.

\section{Surface subsidence characterisation}

Surface subsidence above a block cave mine can be characterised as including both macro and micro deformations. Macro deformations involve ground movements that are visually detectable such as the opening of tension cracks, development of scarps, fracturing and break back of the surface above and around the cave's footprint, and breakthrough of the cave itself to form a large crater. Micro deformations include those detected as tilting ground, small strains and/or vertical and horizontal displacements detectable through deformation monitoring. Although relatively small compared to macro deformations, micro deformations can still be significant in causing differential displacements of several centimetres, which in turn can affect the structural integrity of strain sensitive materials, e.g. concrete. Lupo (1998) reported that micro deformations have been observed up to $250 \mathrm{~m}$ from the perimeter of the caved zone, i.e. crater. Figure 1(a) illustrates the extent of micro deformations (continuous subsidence zone) and macro deformations (caved and fractured zones) in response to block caving as defined by Van As (2003).

Flores and Karzulovic (2003) suggest that topography is one of the most important factors affecting block caving subsidence (Figure 1(b)). Woo et al. (2009) investigated empirical data and characteristics of block caving induced surface subsidence with an emphasis on topography and structural geology. Topography is critical because the scope of surface deformations induced by block cave mining can be amplified and the pattern irregular due to the terrain's ruggedness. This becomes an important consideration where an open pit operation nearing the end of its mine life transitions to an underground block cave operation.

Figure 2 shows examples of macro-scale subsidence patterns captured through satellite imagery. In some cases, topographic effects are minimal (i.e. flat topography) and the visible subsidence features are approximately symmetric (Figure 2(a)). The geometry of the cave collapse structure in such cases lies directly above the footprint of the undercut. Where the topography is irregular, for example where an open pit is present, the resulting cave propagation may again be symmetric (Figure 2(b)) or interactions may develop between the cave and the pit (as well as geological structures) leading to instabilities or nonsymmetric macro deformations (Figure 2(c)).

(a)

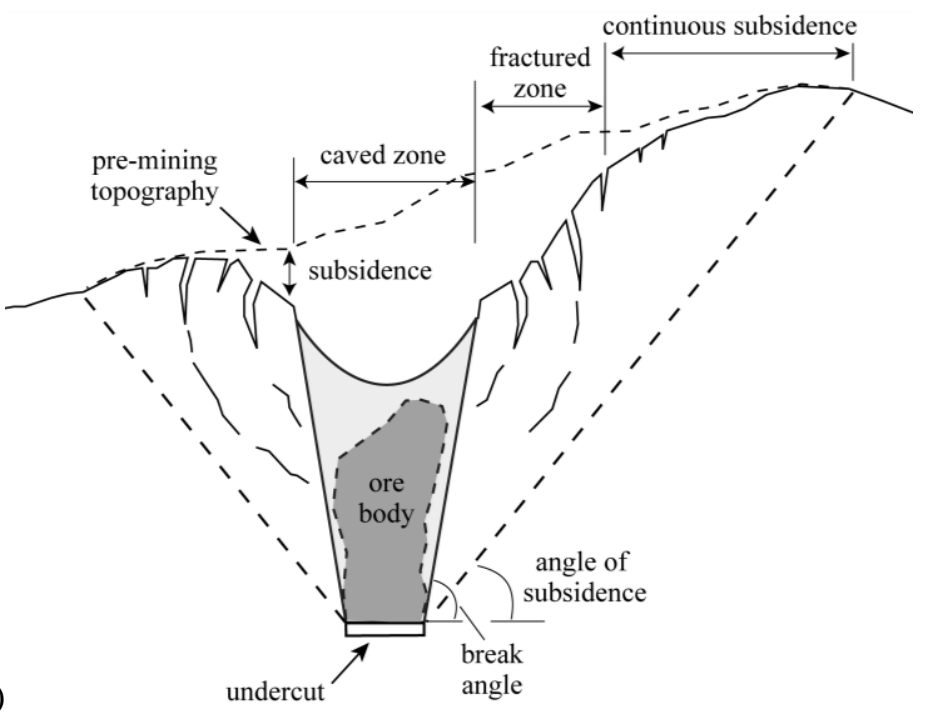

(b)

\begin{tabular}{|c|c|c|c|}
\hline \multirow{2}{*}{$\begin{array}{c}\text { Information } \\
\text { Type }\end{array}$} & \multicolumn{3}{|c|}{ Relative Importance } \\
\hline & Low & Moderate & High \\
\hline \multicolumn{4}{|l|}{ Topography } \\
\hline \multicolumn{4}{|l|}{ Geology } \\
\hline \multicolumn{4}{|l|}{$\begin{array}{l}\text { Structural } \\
\text { Geology }\end{array}$} \\
\hline \multirow{2}{*}{\multicolumn{4}{|c|}{$\begin{array}{l}\text { Geotechrical } \\
\text { Engineering }\end{array}$}} \\
\hline & & & \\
\hline \multicolumn{4}{|l|}{$\begin{array}{l}\text { In Situ } \\
\text { Stress Field }\end{array}$} \\
\hline $\begin{array}{l}\text { Seismicity and } \\
\text { Seismic Risk }\end{array}$ & & & \\
\hline
\end{tabular}

Figure 1 (a) Definition of block caving subsidence zones (after Van As, 2003); (b) Factors affecting block caving subsidence and relative importance (after Flores and Karzulovic, 2003) 
(a)

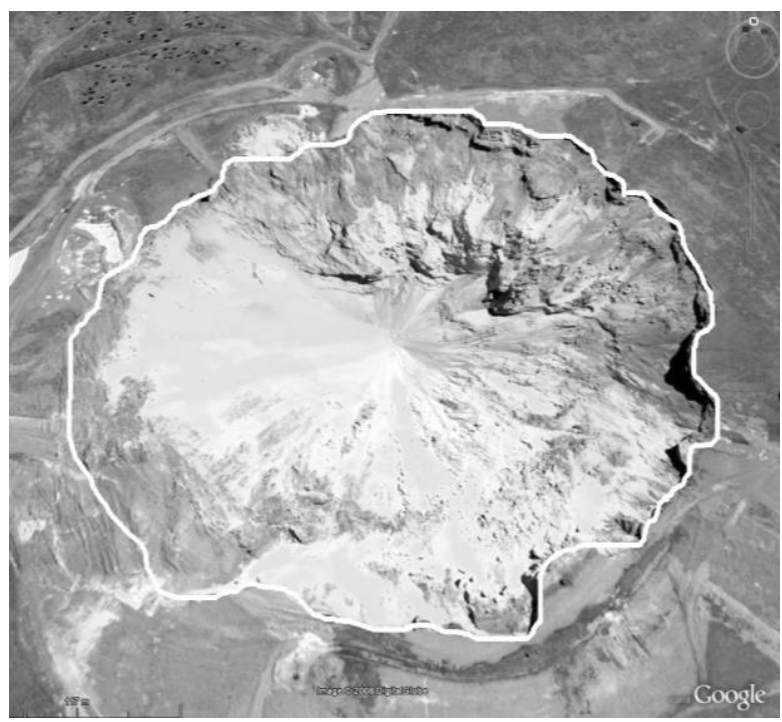

(b)

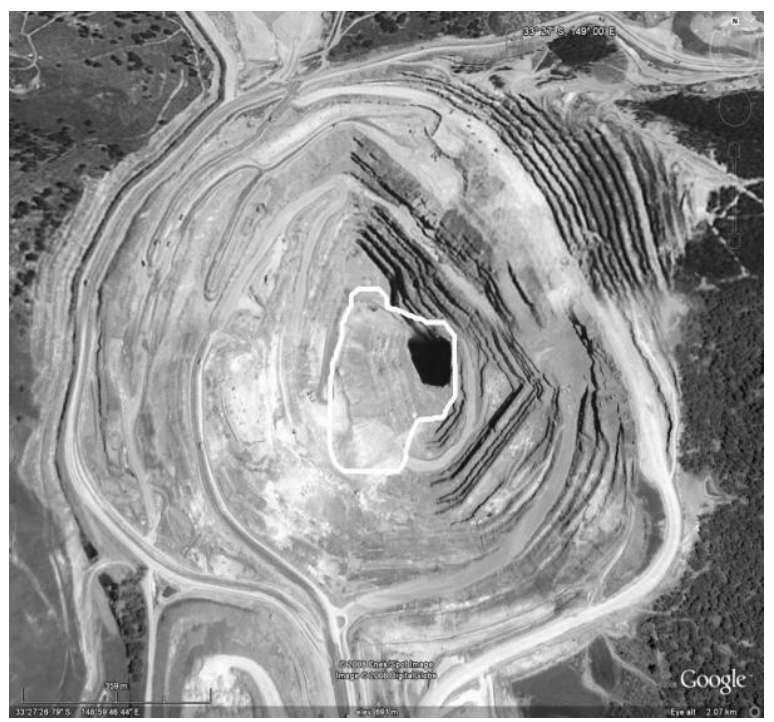

(c)

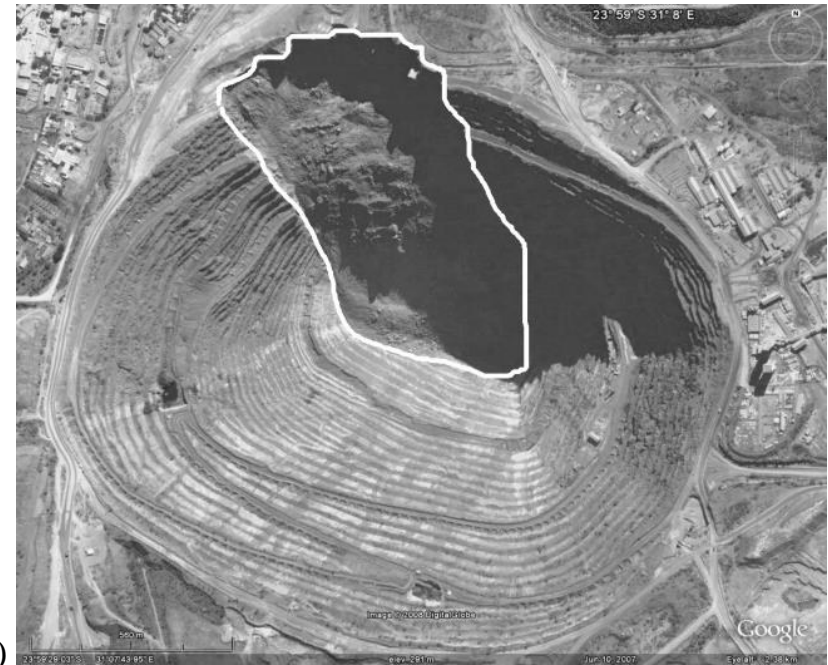

Figure 2 Outlines of surface collapse features where topographic effects are: (a) minor; (b) minor despite the presence of an irregular surface profile; and (c) complex due to undergroundsurface interactions (after Woo et al., 2009)

The question of interactions involving geological structures such as faults, foliation, and/or joint networks, is also important as these create paths of weakness that in turn may control cave propagation (Vyazmensky et al., 2009). Thus in addition to topography, structural geology is another key factor that can contribute towards asymmetry of subsidence. It should be noted that typically, some degree of continuity and symmetry is assumed in most subsidence analyses through the underlying assumptions adopted in carrying out the analysis.

In the case of the Palabora mine in South Africa, interactions between the block cave and open pit geometries are important to understanding the ground deformations that developed. These include the failure of an $800 \mathrm{~m}$ high pit wall shortly after breakthrough of the cave into the bottom of the pit (Figure 2(c)). In effect, the collapse structure and scarps that developed above the cave at Palabora extended beyond the outer perimeter of the pit, threatening mine infrastructure located behind the crest of the slope.

\section{$3 \quad$ Numerical modelling of Palabora}

\subsection{Study site}

The Palabora operation is a porphyry copper mine located in northeastern South Africa (Figure 3). Open pit operations commenced in 1964 with an initial production rate of 30,000 tpd increasing to 82,000 tpd towards 
the end of the pit life in 2002. In total, approximately $960 \mathrm{Mt}$ of ore and 1,300 Mt of waste were extracted from the pit, creating a pit approximately $800 \mathrm{~m}$ deep with a diameter of over 1,650 m. Underground mining was initiated in April 2001 as a block caving operation, with full production being achieved in May 2005. The undercut level is approximately 1,200 m below surface, $400 \mathrm{~m}$ below the pit floor.
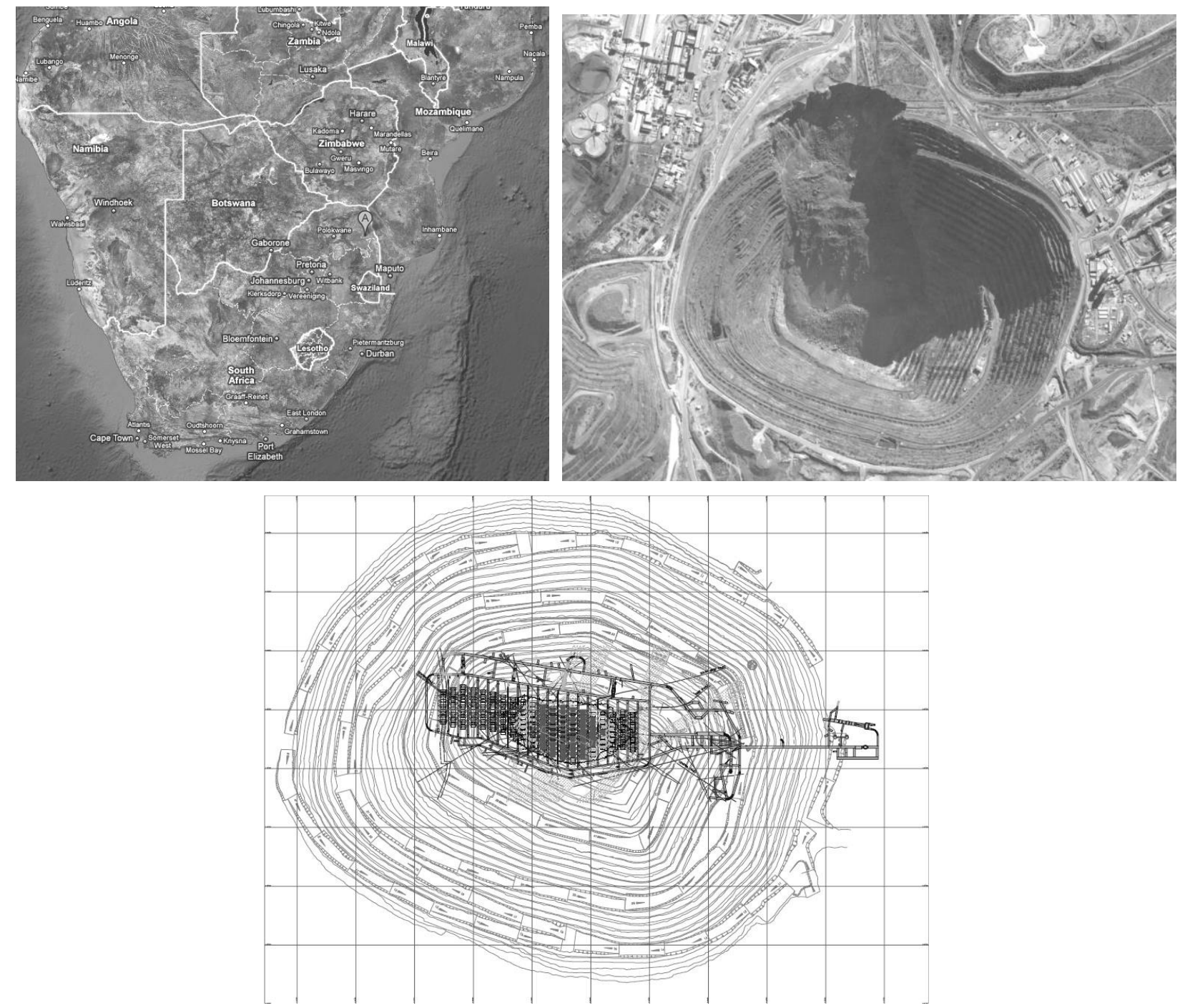

Figure 3 Location, Quickbird image and production layout of the Palabora Mine study area

\subsection{Model development}

Model development has been carried out using the Itasca program FLAC3D (Itasca Consulting Group, 2009). FLAC3D is a 3D finite-difference code for simulating the deformation of a continuum problem domain. The model geometry, including the location of the undercut and shape of the pit, was based on digital mine plans (Figure 4). The shape of the cave was projected from the undercut assuming a break angle of $85^{\circ}$ with constraints imposed by measuring the outline of the cave breakthrough into the pit bottom from satellite Quickbird images (e.g. Figure 3). Figure 5 shows the assumed cave geometry divided into three lifts representing different stages in cave development over time.

The modelling results reported here focus on the influence of topography at Palabora, i.e. the interactions between the complex 3D geometries of the cave and open pit. For this, a simple Mohr-Coulomb elasto-plastic constitutive model was used with different properties being defined for the host rock (weathered pyroxenite), orebody (carbonatite) and caved material. Future modelling will explore the influence of geological heterogeneity through the inclusion of structural domains and use of other constitutive models including strain softening and ubiquitous joint. Rock mass properties were adopted based on estimates derived from laboratory testing and field mapping data (i.e. rock mass rating (RMR)), as 
reported by Piteau Associates (2000). In the case of the host rock, the medium through which the cave induced subsidence develops, a parametric analysis was performed sampling from the range of properties estimated for the pyroxenite. Table 1 reports the modelling input properties used.

The development of the block cave was modelled by changing the material properties of the ore above the undercut to those of broken rock (i.e. caved ore) in step with the upward propagation of the cave. In addition, the stresses within the cave had to be reset with each modelled advance of the cave back, from those initialised for the intact orebody to those reflecting the self-weight of caved rock (Figure 6).

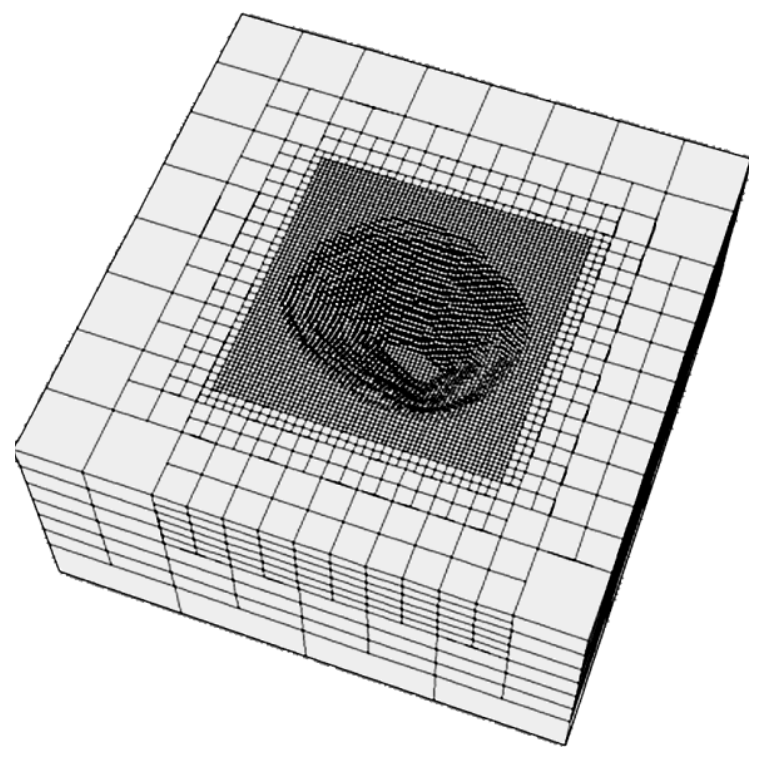

Figure 4 FLAC3D Palabora model

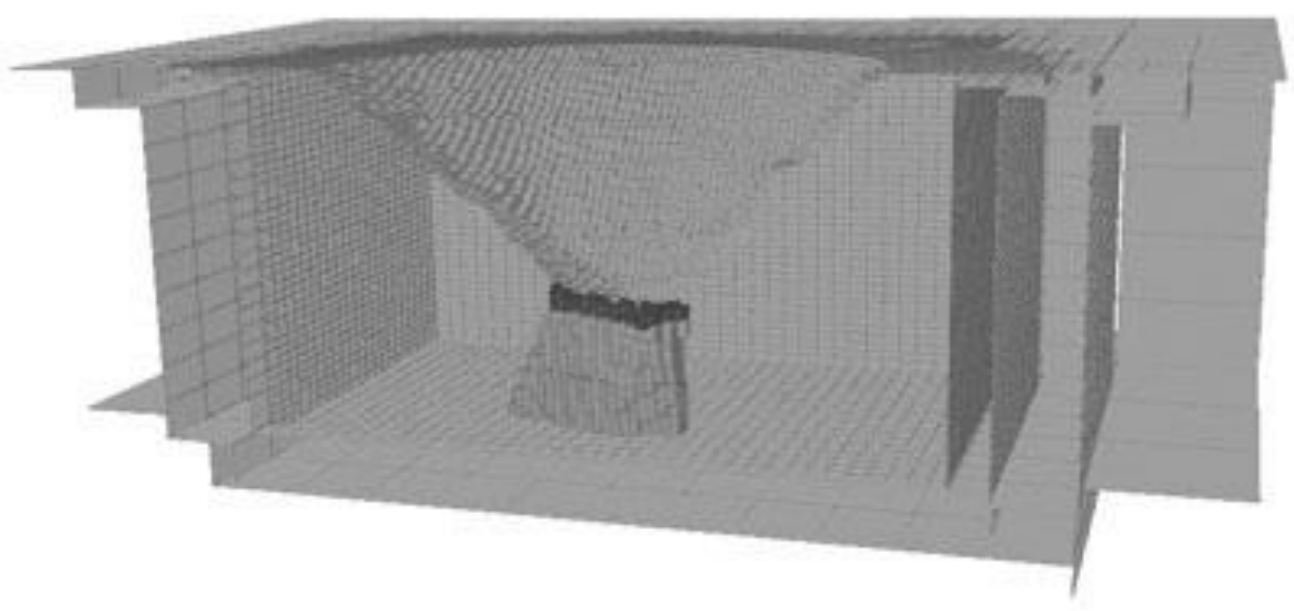

Figure 5 FLAC3D model of Palabora open pit showing pit and cave geometry, together with caving sequencing

Table 1 Rock mass properties used for FLAC3D models

\begin{tabular}{llllll}
\hline & $\begin{array}{l}\text { Density } \\
\left(\mathbf{k g} / \mathbf{m}^{\mathbf{3}}\right)\end{array}$ & $\begin{array}{l}\text { Bulk Modulus } \\
(\mathbf{G P a})\end{array}$ & $\begin{array}{l}\text { Shear Modulus } \\
(\mathbf{G P a})\end{array}$ & $\begin{array}{l}\text { Cohesion } \\
(\mathbf{M P a})\end{array}$ & $\begin{array}{l}\text { Friction } \\
\text { Angle }(\mathbf{d e g} .)\end{array}$ \\
\hline Host rock & 3,100 & $2.1-9.4$ & $1.3-5.7$ & $1.6-2.9$ & $23-36$ \\
Orebody & 3,100 & 9.4 & 5.7 & 2.9 & 36 \\
Waste rock & 2,300 & 0.42 & 0.19 & 0 & 35 \\
\hline
\end{tabular}


(a)

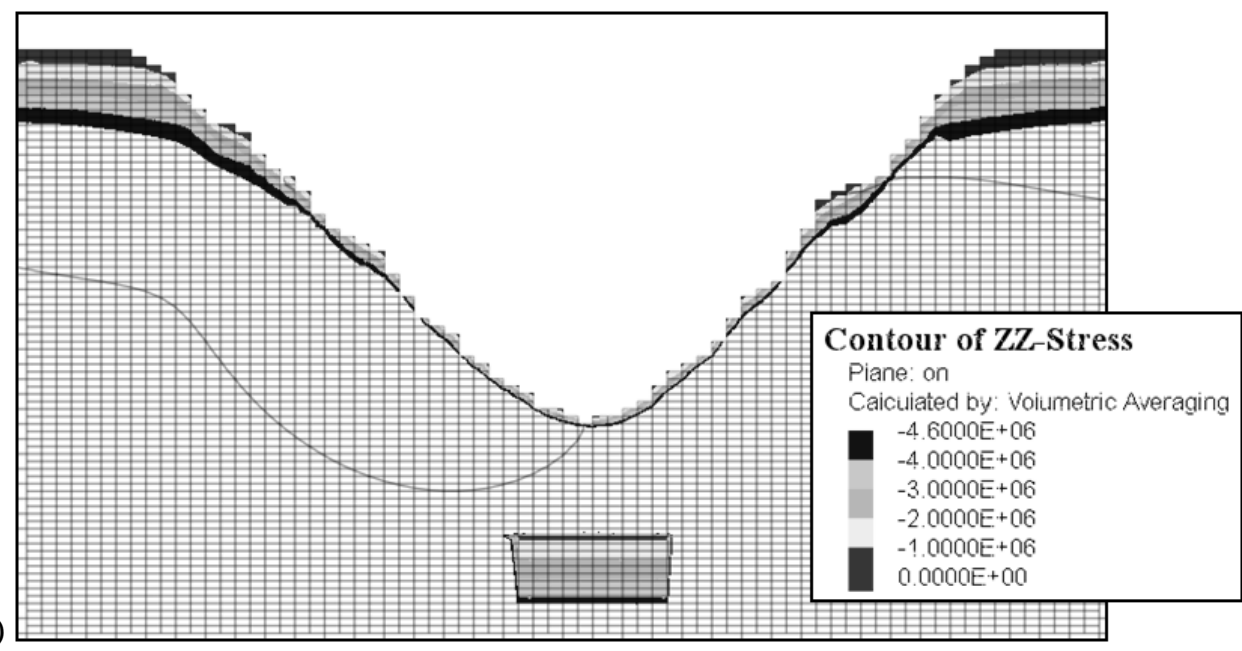

(b)

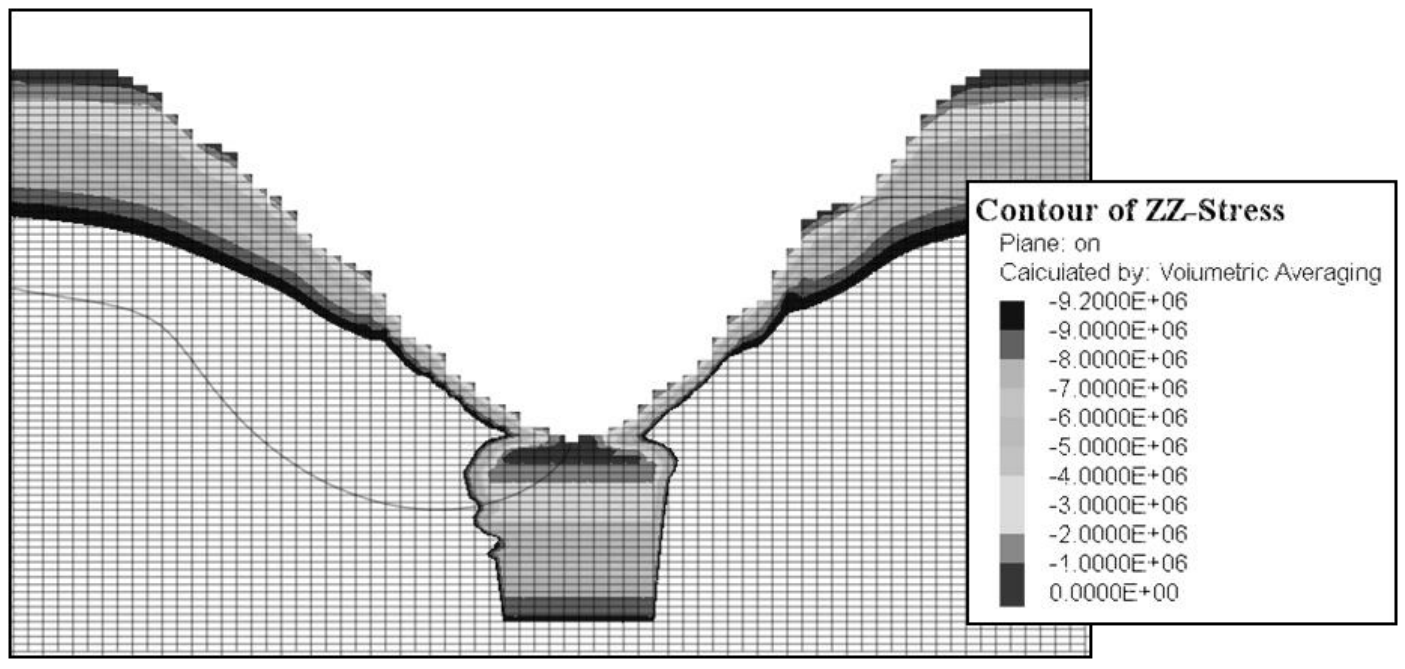

Figure 6 Resetting of initial stresses within caved zone to those representing the self weight of the caved ore, for: (a) $170 \mathrm{~m}$ cave height $(40 \%)$; and (b) $390 \mathrm{~m}$ cave height $(100 \%)$. Vertical stress contours are in $\mathbf{P a}$

\subsection{Numerical modelling results}

Figures 7 and 8 show the vertical displacements calculated by FLAC3D using the upper and lower limits of the rock mass properties for the pyroxenite host rock (as reported in Table 1). A vertical displacement contour cutoff of $3 \mathrm{~cm}$ is applied based on the National Coal Board's (1975) minimum threshold for 'very slight' damage to surface infrastructure. Using the upper bound rock mass properties (Figure 7), the $3 \mathrm{~cm}$ subsidence boundary changes very little as the cave develops and remains largely centred in the bottom of the pit. A significantly different response was obtained however, when the lower bound properties were used for the host rock (Figure 8). For this case, the stress-strain interaction between the cave and open pit results in yielding and increased displacements in the north wall of the pit. The location is approximately coincident with that of a large $800 \mathrm{~m}$ high pit slope failure that occurred in late 2004 and early 2005 . Figure 9 compares the outline of the pit slope failure with the numerical modelling results from Figure 8(A-2). These results, although preliminary, suggest that the topography of the open pit was an important factor influencing the cave propagation, drawing it towards the north such that it undermined the toe of the slope eventually causing it to fail.

These models demonstrate how significantly different results can be obtained by simply varying the input properties for one material in the model within a range of acceptable values (e.g. Table 1). The presence of the 2005 pit slope failure provides one means to calibrate and constrain the model, but only in the form of a back analysis. Carrying out a predictive forward analysis requires further means to constrain the model. 


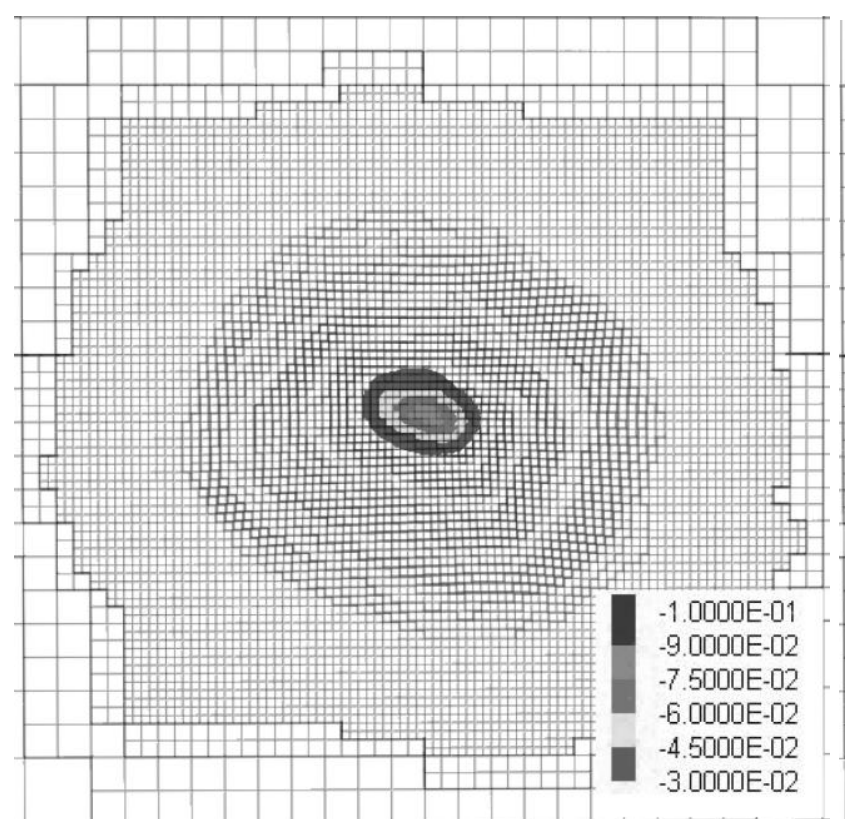

A-1

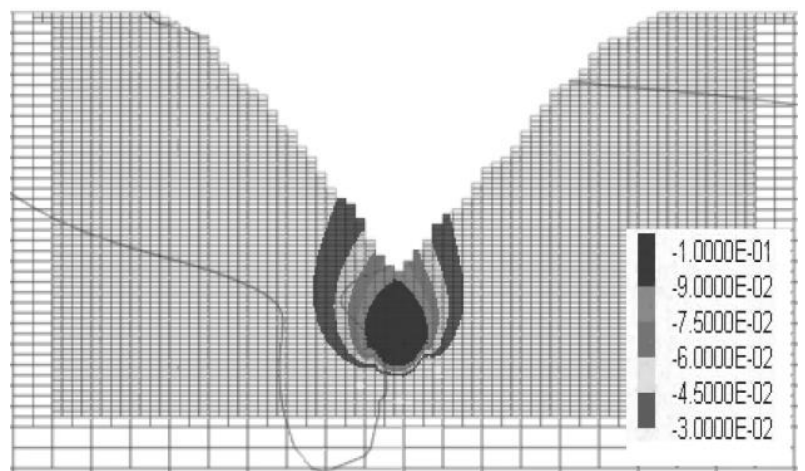

B-1

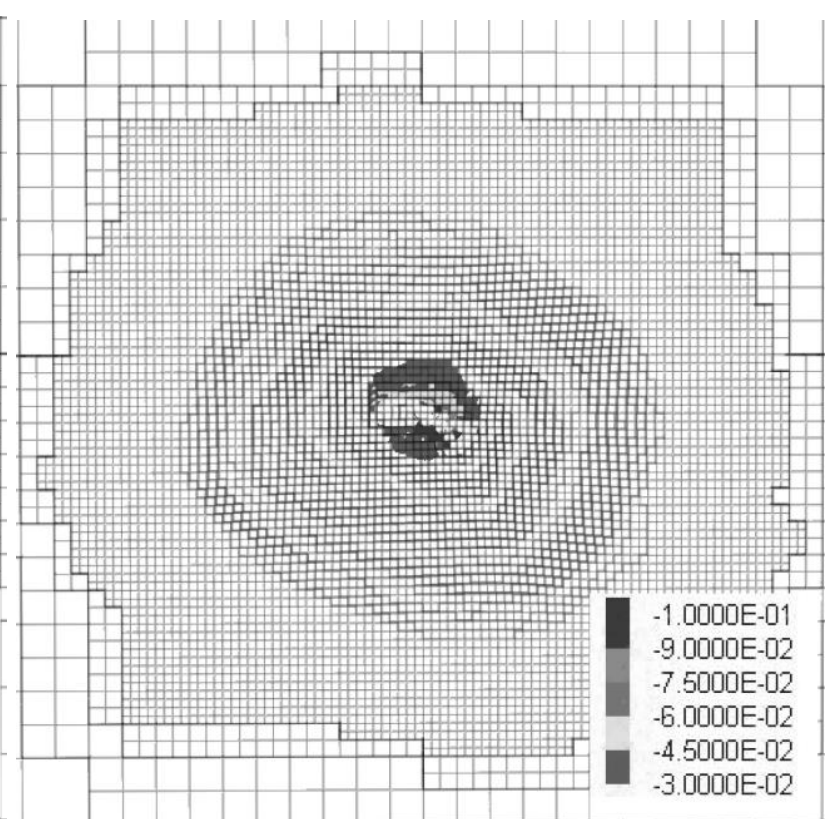

A-2

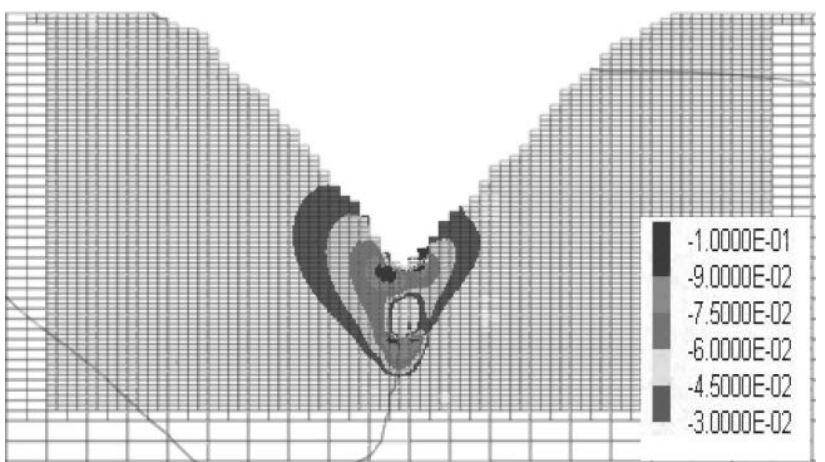

B-2

Figure 7 FLAC3D results assuming upper limit properties for host rock, showing vertical displacements greater than $3 \mathrm{~cm}$ in plan view (A) and along a north-south section (B), for cave heights of $40 \%$ (1) and $100 \%$ (2), i.e. at cave breakthrough. Vertical displacement contours are in metres. Displacements greater than $25 \mathrm{~cm}$ are not contoured (maximum displacements above the cave exceed $13 \mathrm{~m}$ ) 


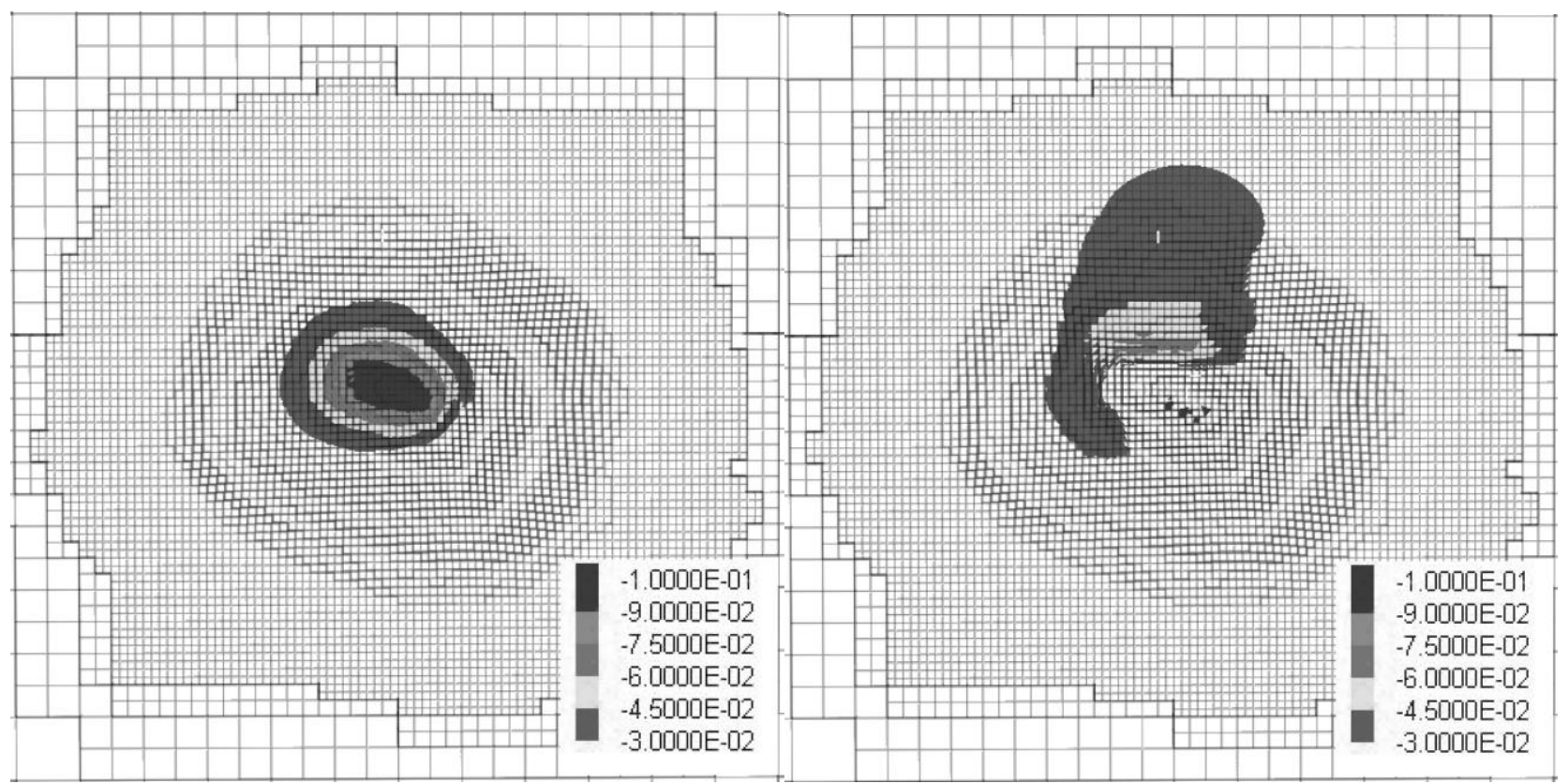

A-1

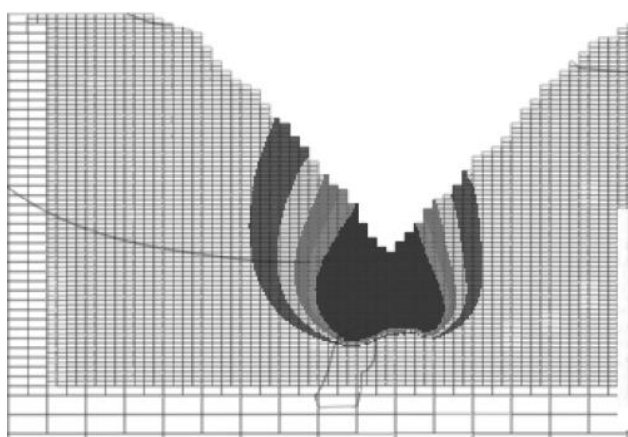

B-1
A-2

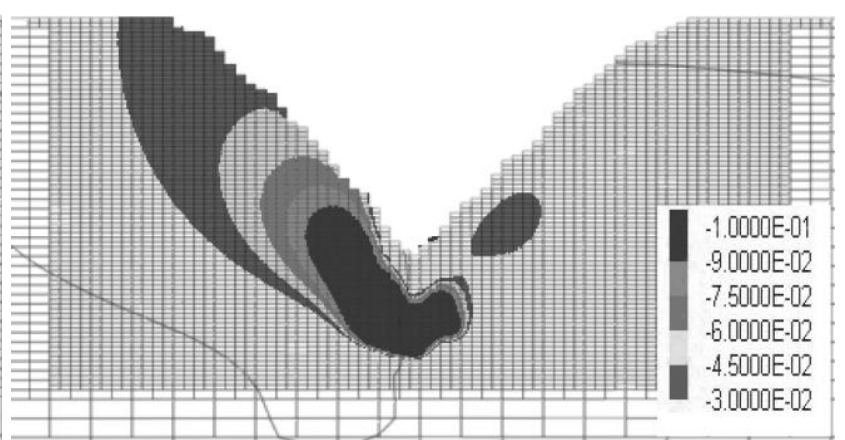

B-2

Figure 8 FLAC3D results assuming lower limit properties for host rock, showing vertical displacements greater than $3 \mathrm{~cm}$ in plan view (A) and along a north-south section (B), for cave heights of $40 \%(170 \mathrm{~m})(1)$ and $100 \%(390 \mathrm{~m})(2)$. Z-Displacement contours are in metres (maximum displacement for case (2) is $12.8 \mathrm{~m}$ )

\section{$4 \quad$ Satellite-based InSAR monitoring}

Space-borne Synthetic Aperture Radar (SAR) involves the use of satellite-based microwave radar to remotely observe characteristics of ground terrain. With repeated orbits and image capture (referred to as stacks), InSAR data can be processed to resolve 3D information of surface deformations by analysing differences in the phase between waves being transmitted and received by the satellite (Zebker and Rosen, 1994). Ground deformations on the scale of centimetres to millimetres can be detected for a surface area resolution of several square metres using these techniques.

This ability provides a means to monitor mining induced differential strains, including small strain $(<1 \%)$, that develop across an irregular surface topography. To explore this application in more depth, a partnership has been developed between MDA Systems Ltd., the University of British Columbia, Simon Fraser University, the Canadian Space Agency, Rio Tinto and BHP Billiton. The principal objective is to develop an advanced information product integrating InSAR imagery, geology, geotechnical data sets, and 3D numerical modelling to assist mining decision makers in their development of safe and efficient block caving and open pit mining operations. 


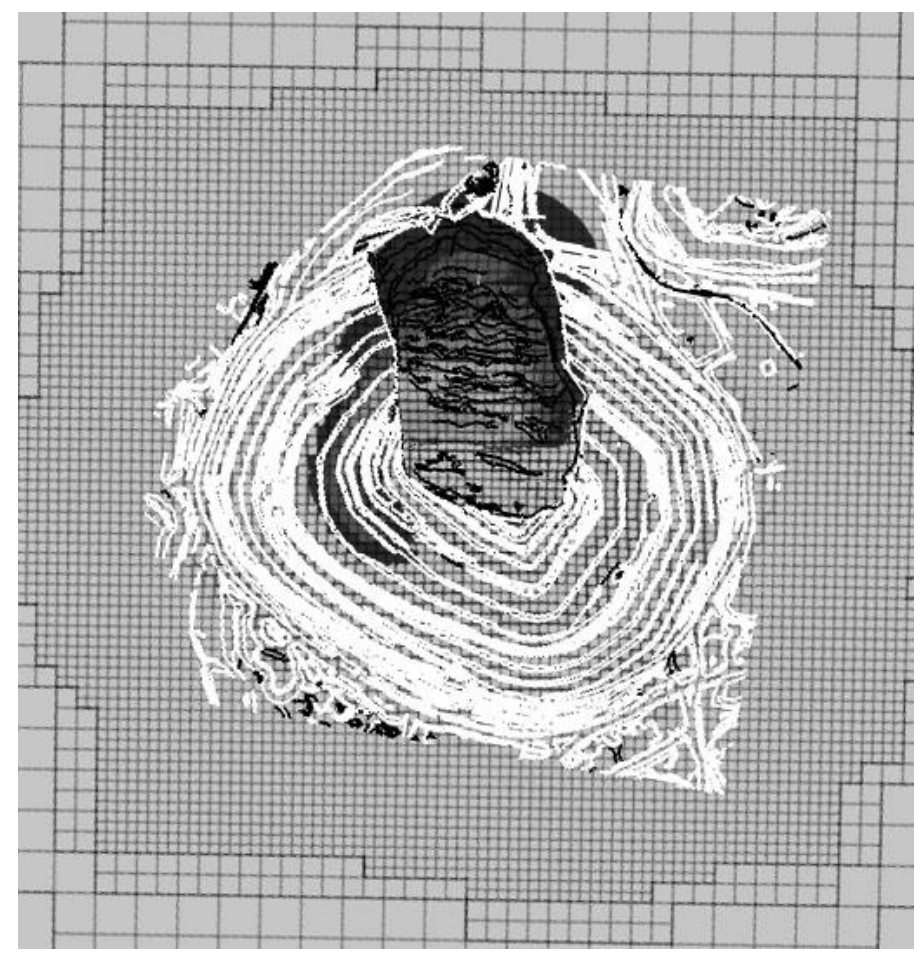

\section{Figure 9 Comparative analysis of numerical modelling results (see Figure 8, A-2) with DEM data and outline of pit slope failure}

Figure 10(a) shows the InSAR results from the analysis of RADARSAT-1 images $(8 \mathrm{~m}$ surface area resolution) for Palabora recorded for the two year period following the 2005 north wall failure. The images are horizontally flipped (i.e. east and west are reversed relative to north) due to the means by which the data is recorded by the satellite. The results show that most of the displacements detected $(1-21 \mathrm{~mm})$ are concentrated along the north wall, especially towards the east along its crest. These would appear to be related to the instability of the pit wall in response to the cave breakthrough below. Smaller displacements $(<5 \mathrm{~mm})$ are also seen in the lower south wall, most likely the result of caving induced subsidence. Behind the slope crests and around the mine area in general, little subsidence is detected during this period. Figure 10(b) shows displacements recorded between March and July 2008. During this time period, only small strain subsidence $(<5 \mathrm{~mm})$ was recorded in the peripheral area of the mine. Most of the recorded displacements are concentrated along the scarp of the north wall failure.

Comparing these displacements to those modelled in Figure 8, representing a time period corresponding to the breakthrough of the cave into the pit floor, both the areas of activity and the magnitudes of displacement agree reasonably well. With further refinements to the cave geometry through the added constraint of microseismic data, as well as by incorporating more geological heterogeneity in the form of structural domains and discrete structures (ubiquitous joints), work will progress towards improving these preliminary results in terms of both their spatial and temporal evolution.

With respect to current and future cave induced ground deformations at Palabora, the smaller temporal timeframe requires higher resolution imagery. With the December 2007 launch of RADARSAT-2, Canada's second generation commercial SAR satellite, surface area resolutions approaching $2 \times 2 \mathrm{~m}$ can now be achieved. Together with improvements in data processing and inversion of the phase components (atmosphere, height error and displacement corrections) developed in-house by MDA Systems Ltd., significant gains have been made in the robustness of the InSAR solution (Rabus et al., 2009). Figure 11 shows the most recent InSAR imagery captured for Palabora for a 96 day time window between April and July 2009. This data shows that most of the displacements $(<30 \mathrm{~mm})$ correspond to ongoing activity around the scarp of the 2005 north wall failure. Otherwise, displacements corresponding to caving induced subsidence are less than $10 \mathrm{~m}$ for this time period. Future FLAC3D modelling, will concentrate on back analysing these displacements for the different time intervals represented by the high resolution RADARSAT-2 image stacks. 


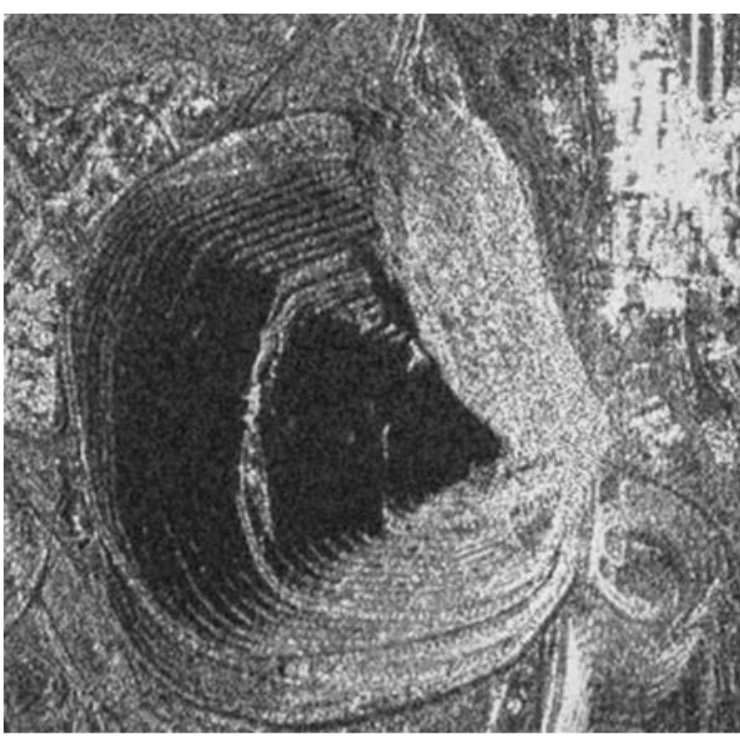

(a) October 2005 to November 2007

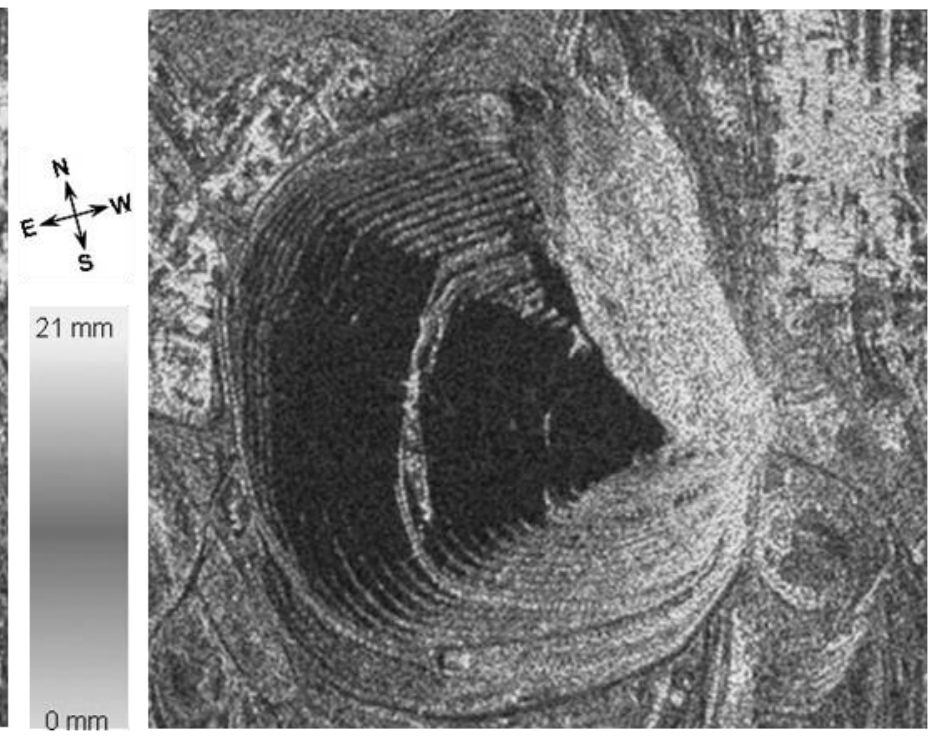

(b) March 2008 to July 2008

Figure 10 RADASAT-1 InSAR results for Palabora for various time periods (8 $\mathrm{m}$ surface resolution)

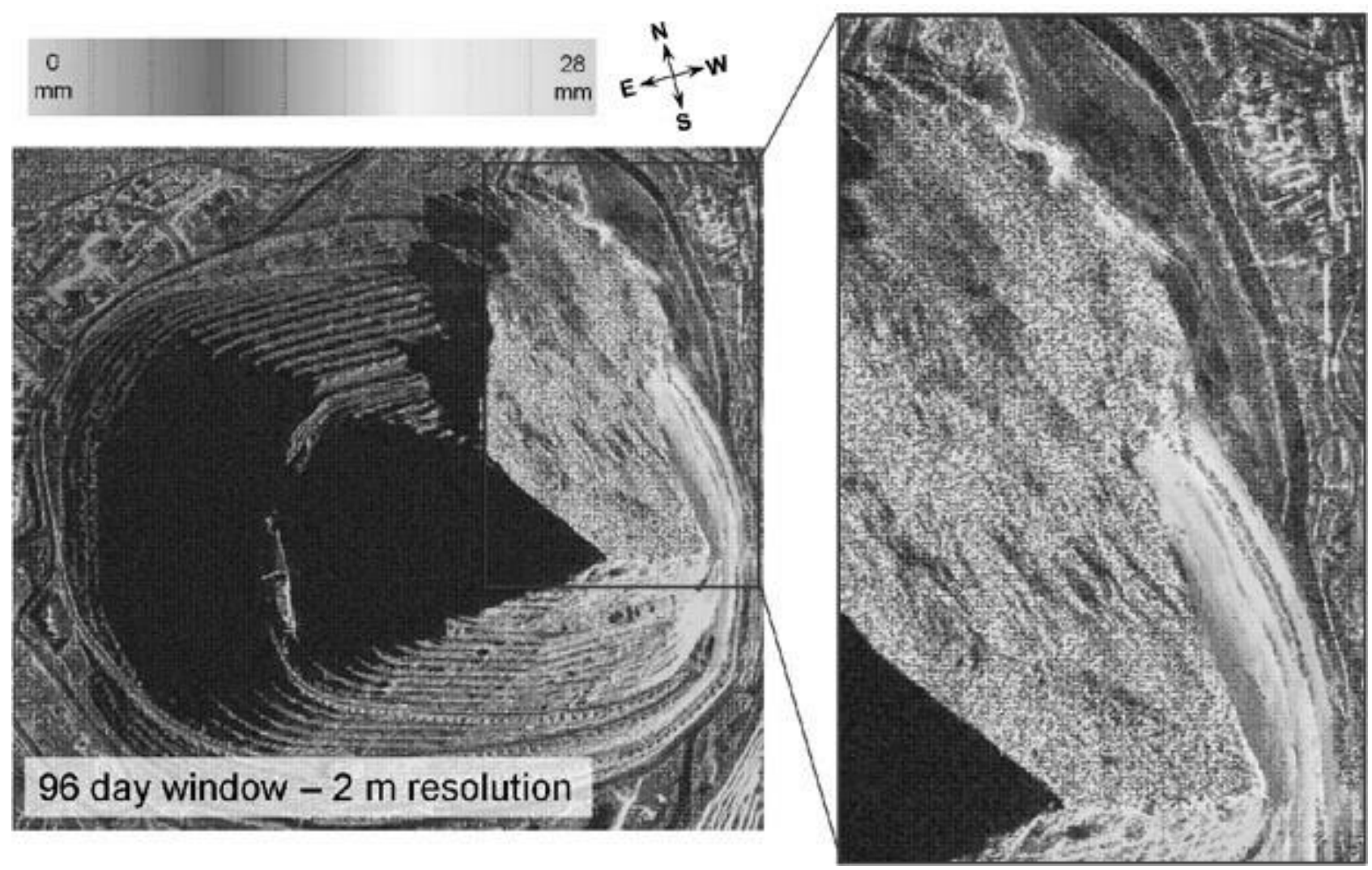

Figure 11 RADASAT-2 InSAR results for Palabora between April and July 2009 (2 m surface resolution)

\section{$5 \quad$ Integration and 3D visualisation}

The acquisition of geological and geotechnical data is important in mine design, numerical modelling and subsidence prediction. However, the massive volumes of data generated from in situ surveys and mine operations becomes difficult to manage, store and utilise. Improved computer performance and new software developments are changing this situation. Easy-to-use integrated subsidence management systems with 3D 
visualisation and data immersion can be envisaged, linking monitoring, analysis and prediction to allow researchers and practitioners from varied fields to better understand caving induced subsidence development.

The 3D numerical modelling and InSAR deformation mapping being carried out as part of this study will be integrated and visualised using state-of-the-art data immersion platforms, including a Cyviz Vizwall 3D stereo rear projection system that forms part of the University of British Columbia's Earth amd Ocean Sciences' 3D Data Immersion Facility. Spatial databases are being developed to integrate the different data sets being used for model development (geological, geotechnical, operational, etc.) into an interactive 3D visualisation environment (Figure 12(a)). These data models will then be further combined with the results of 3D numerical modelling, together with the monitoring data used to constrain the models (InSAR, geodetic, microseismic, etc.), for full immersion into a 3D virtual reality environment (Figure 12(b)). Together, these integrated models will serve as a 3D mine subsidence safety model for the studied site.

(a)

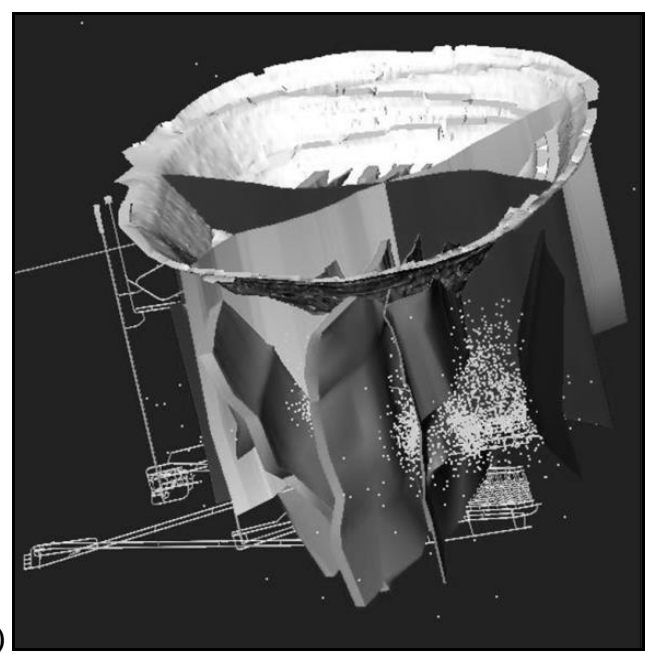

(b)

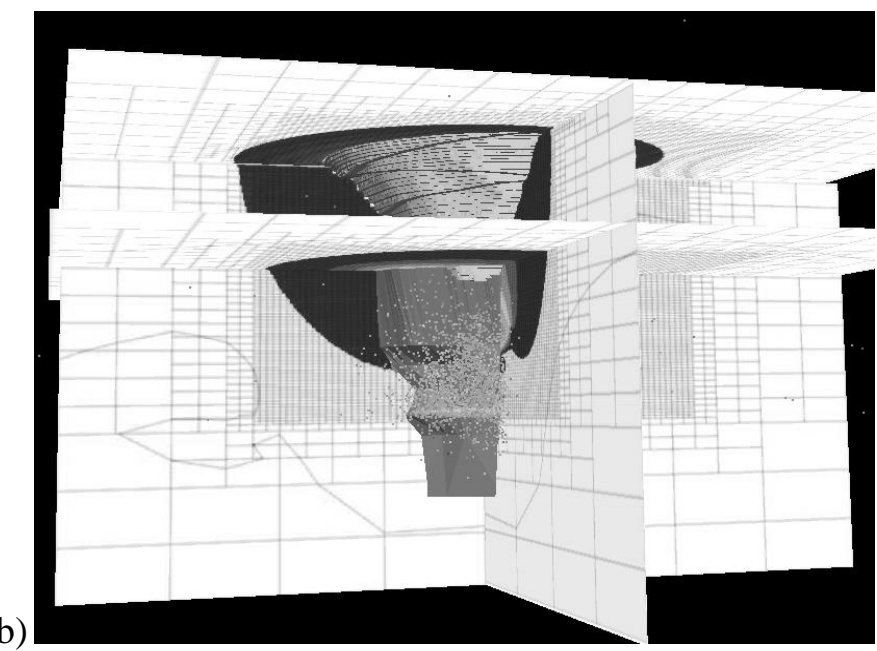

Figure 12 (a) Integrated data model for Palabora combining mine shell, geology and microseismic data; (b) Data model integrated with FLAC3D displacement modelling results

\section{Conclusions}

Results are presented from preliminary 3D numerical modelling of block caving induced surface subsidence at the Palabora mine. The results demonstrate that the modelled outcome is heavily dependent on the rock mass properties assumed, with significantly different results being obtained for input properties sampled within the range of values derived from laboratory testing and field-based estimates. Preliminary results are then presented from InSAR deformation monitoring, which are used as a means to calibrate and constrain the 3D numerical models. These data sets will be combined with all available monitoring constraints, including geodetic and microseimic monitoring, to more fully develop and constrain the 3D numerical models as well as the interpretation of the InSAR monitoring results.

Together, the preliminary modelling results suggest that the surface topography in the form of the deep pit at Palabora was a contributing factor that influenced the propagation of the block cave beneath it, and that its breakthrough into the pit floor had a stronger interaction with the north wall than the south wall of the pit. Agreement was found between these zones of ground movement and the location of the 2005 north wall pit slope failure. Future work will continue to improve the spatial and temporal correlation between InSAR measured ground displacements, geodetic and microseismic monitoring data, and the 3D numerical models, with the focus of integrating these data sets to be visualised within a 3D data immersion environment. 


\section{Acknowledgements}

This work is funded through a grant from the Canadian Space Agency (contract \#F028-07-1686) and a Collaborative Research and Development grant from the Natural Sciences and Engineering Research Council of Canada (NSERC) in partnership with Rio Tinto. The authors wish to thank Rio Tinto, Dr Stefan Glazer and the Palabora Mine for providing data, and Dr Andre Van As (Rio Tinto Technical Services), Guy Aubé (Canadian Space Agency) and Corey Froese (Alberta Geological Survey) for their technical guidance.

\section{References}

Beck, D. and Pfitzner, M. (2008) Interaction between deep block caves and existing, overlying caves or large open pits, in Proceedings 5th International Conference and Exhibition on Mass Mining, MassMin 2008, H. Schunnesson and E. Nordlund (eds), 9-11 June 2008, Luleå, Sweden, Luleå University of Technology Press, Luleå, pp. 381-391.

Flores, G. and Karzulovic, A. (2003) Geotechnical guideline for a transition from open pit to underground mining: Geotechnical characterization, Report to International Caving Study II, Julius Kruttschnitt Mineral Research Centre, Brisbane, 114 p.

Gilbride, L.J., Free, K.S. and Kehrman, R. (2005) Modeling block cave subsidence at the Molycorp, Inc., Questa mine, in Proceedings 40th US Rock Mechanics Symposium, Anchorage, paper 05-881.

Itasca Consulting Group (2009) FLAC3D (Fast Lagrangian Analysis of Continua in 3Dimensions), Version 4.0, Itasca Consulting Group, Inc: Minneapolis.

Karzulovic, A., Cavieres, P. and Pardo, C. (1999) Caving subsidence at El Teniente mine, in Proceedings Symposium on Mining Engineering, SIMIN99, Santiago.

Laubscher, D.H. (2000) Block Cave Manual, Design Topic: Subsidence, Julius Kruttschnitt Mineral Research Centre, Brisbane.

Lupo, J. (1998) Large-scale surface disturbance resulting from underground mass mining, International Journal of Rock Mechanics and Mining Science and Geomechanics Abstracts, Vol. 35, No. 4/5, p. 399.

National Coal Board (1975) Subsidence Engineers Handbook, 2nd edition, Coal Board Mining Department, London, p. 111.

Piteau Associates (2000) Numerical Modelling of the Effects of Open Pit Deepening and Block Cave Mining on the Stability of the East and North Walls, Palabora Mining Company Phalaborwa, South Africa Copper Open Pit Project 686-UG, $138 \mathrm{p}$.

Rabus, B., Eberhardt, E., Stead, D., Ghuman, P., Nadeau, C., Woo, K., Severin, J., Styles, T. and Gao, F. (2009) Application of InSAR to constrain 3D numerical modelling of complex discontinuous pit slope deformations, in Proceedings 3rd International Symposium on Rock Slope Stability, Slope Stability 2009, Santiago, Chile, 9-11 November, Universidad de los Andes, CD-ROM, $11 \mathrm{p}$.

Sainsbury, B., Pierce, M.E. and Mas Ivars, D. (2008) Analysis of caving behaviour using a synthetic rock massubiquitous joint rock mass modelling technique, in Proceedings 1st Southern Hemisphere International Rock Mechanics Symposium, SHIRMS08, Vol. 1 - Mining and Civil, Y. Potvin, J. Carter, A. Dyskin and R. Jeffrey (eds), Australian Centre for Geomechanics, Perth, Australia, pp. 343-252.

van As, A. (2003) Subsidence Definitions for Block Caving Mines, Technical Report, Rio Tinto Technical Services, $59 \mathrm{p}$.

Vyazmensky, A. (2008) Numerical Modelling of Surface Subsidence Associated with Block Cave Mining Using a Finite Element/Discrete Element Approach, PhD Thesis, Simon Fraser University, 239 p.

Vyazmensky, A., Stead, D., Elmo, D. and Moss, A. (2009) Numerical analysis of block caving-induced instability in large open pit slopes: A finite element/discrete element approach, Rock Mechanics and Rock Engineering, DOI 10.1007/s00603-009-0069-6.

Woo, K., Eberhardt, E. and van As, A. (2009) Characterization and empirical analysis of mining-induced subsidence over block caving operations, in Proceedings Symposium and Workshops on Rock Engineering in Difficult Conditions, 3rd Canada-US Rock Mechanics Symposium, Toronto, M. Diederichs and G. Giovanni (eds).

Zebker, H.A. and Rosen, P.A. (1994) On the derivation of coseismic displacement fields using differential radar interferometry: The Landers earthquake, Journal of Geophysical Research, Vol. 99, No. B10, p. 19, pp. 617-619. 